\title{
ОБЗОР ИХТИОФАУНЫ РЕКИ БУЮНДА (бассейн р. Колыма)
}

\author{
Шестаков А. В., Грунин С. И. \\ ФГБУН Институт биологических проблем Севера ДВО РАН, г. Магадан \\ E-mail: a.v.shestakov@mail.ru
}

\begin{abstract}
Рассмотрены современный таксономический состав и особенности биологии рыбообразных и рыб р. Буюнда (бассейн р. Колыма). Ихтиофауна включает 21 таксон видового и подвидового рангов, относящихся к 19 родам, 12 семействам, 8 отрядам и 2 классам. Преобладают представители отрядов карпообразных и лососеобразных, которые определяют облик всей ихтиофауны реки. Отмечены два региональных эндемика Северо-Востока Азии - сибирский чукучан и колымский подкаменщик.
\end{abstract}

Ключевые слова: пресноводные рыбы, р. Буюнда, бассейн р. Колыма, фауна рыб, экотипы.

DOI: 10.34078/1814-0998-2020-4-90-96

Последние десятилетия характеризуются климатическим трендом атмосферы Земли в сторону потепления, что особенно сильно выражено в субарктических и арктических районах Северного полушария. Подобные климатические изменения представляют потенциальную угрозу устойчивости пресноводных экосистем, из которых наиболее важные - крупные северные реки Сибири и Северо-Востока России. Их ценность заключается в наличии значительных запасов промысловых лососеобразных и карпообразных рыб. Поэтому изучение биологического разнообразия рыб в отдаленных и труднодоступных регионах приобретает в настоящее время особенно важное значение.

Река Буюнда является крупным правым притоком среднего течения бассейна Колымы. До настоящего времени огромный бассейн Колымы (крупнейший на Северо-Востоке России) остается наименее изученным в ихтиологическом отношении водоемом региона, а некоторые сведения о его ихтиофауне содержатся в немногочисленных работах (Новиков, 1966; Кириллов Ф., 1972; Черешнев, Кириллов, 2007; Кириллов и др., 2016). Причем подавляющее большинство данных о фауне и биологии рыб относится к нижнему течению р. Колыма, где традиционно существовал промысел, тогда как значительная часть верхнего и среднего течений с многочисленными притоками, в том числе и р. Буюнда, была едва затронута эпизодическими исследованиями (Дрягин, 1933; Скопец,

(С Шестаков А. В., Грунин С. И., 2020
1983, 1985; Штундюк, Скопец, 1988; Никишин, Леонов, 2000).

Цель работы - изучить современный таксономический состав ихтиофауны и особенности биологии некоторых видов рыб р. Буюнда (бассейн среднего течения р. Колыма).

\section{МАТЕРИАЛ И МЕТОДЫ}

В работе использованы материалы, собранные в июле 2018 г. в среднем и нижнем течении p. Буюнда, которая имеет протяженность 434 км

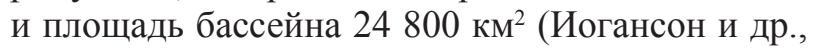
1970). Река берет начало на Кегалинском хребте, протекает по Колымскому нагорью и в нижнем течении выходит в Сеймчано-Буюндинскую впадину (см. рисунок). Рыб отлавливали ставными сетями разной длины, изготовленными из дели с ячеей от 10 до 45 мм, спиннингом, поплавочной удочкой и мальковым неводом. Количественная характеристика материала приводится в ходе изложения.

Материалы обрабатывали в полевых и камеральных условиях, используя стандартные ихтиологические методики (Правдин, 1966; Лакин, 1990). У всех рыб определяли стандартную длину $(S L)$ и длину по Смитту $(F L)$, массу тела, пол, стадию зрелости гонад и возраст, который оценивали по чешуе, взятой выше боковой линии на уровне задней части спинного плавника.

Статус и номенклатура таксонов приводятся с учетом сводок современных каталогов рыб (Парин и др., 2014; Eschmeyer’s..., 2020). 


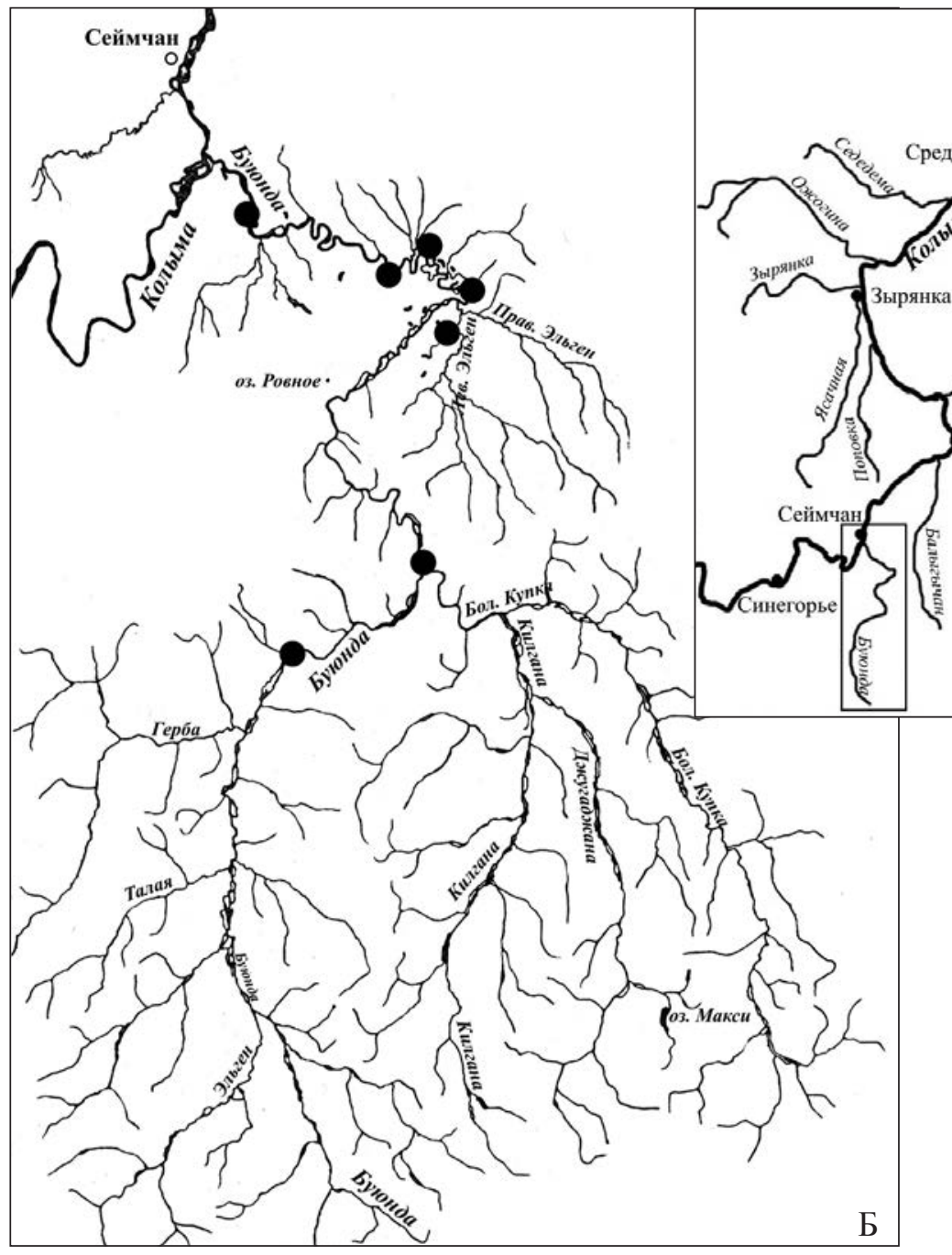

Рисунок. Карта-схема района исследований и места сбора материала (•). А - бассейн р. Колыма, Б - бассейн p. Буюнда

Figure. Map of the investigation area and (•) sampling spots. A - Kolyma River basin, Б - Buyunda River basin

\section{РЕЗУЛЬТАТЫ И ОБСУЖДЕНИЕ}

По результатам проведенного обследования, а также по литературным данным фауна рыбообразных и рыб бассейна р. Буюнда представлена 21-м таксоном видового и подвидового рангов, относящихся к 19 родам, 12 семействам, 8 отрядам и 2 классам (табл. 1).

В ихтиофауне преобладают представители отрядов карпообразных (3 семейства, 6 родов и 7 видов) и лососеобразных (также 3 семейства, 6 родов и 7 видов). Самое многочисленное по количеству родов (4) и видов (5) семейство карповых. Далее следует семейство сиговых (3 рода и 4 вида), лососевых (2 и 2) и окуневых (также 2 и 2). Остальные 8 семейств (миноговые, балиторовые, чукучановые, щуковые, хариусовые, налимовые, колюшковые и рогатковые) - монотипические (1 род, 1 вид).

Ниже приводятся биологические характеристики относительно массовых видов рыб в наших уловах 2018 г.

Обыкновенный гольян. Пресноводный, речной вид, который широко распространен в бассейне Колымы. В р. Буюнда встречается повсе- местно. Является стайной рыбой и предпочитает прибрежные участки рек и проток с прозрачной водой, галечным грунтом и достаточно быстрым течением.

Разовый улов, проведенный 13 июля 2018 г. по основному руслу Буюнды, включал рыб с длиной 25.2-70.8 (в среднем 52.3 \pm 0.97 ) мм и массой тела 0.18-4.61 (2.12 \pm 0.10$)$ г (табл. 2). Самки в исследуемой выборке были длиной от 40.2 до 70.8 мм при средней массе тела 2.4 г. Самцы при средней массе 2.12 г имели длину от 43.2 до 60.1 мм. Соотношение самцов и самок в улове было примерно равным. Минимальные размеры зрелых самцов составили 32 мм и 1.33 г, самок50.9 мм и 1.86 г.

Обыкновенный гольян питается водорослями, водными беспозвоночными, упавшими в воду насекомыми. В свою очередь, выступает объектом питания щуки, налима, ленка, окуня. Непромысловый вид.

Сибирский чукучан. Эндемичный азиатский подвид североамериканского чукучана, многочисленный, типично пресноводный. Встречается на всем протяжении равнинных 
Таблица 1. Состав ихтиофауны р. Буюнда

Table 1. Buyunda River ichthyofauna composition

\begin{tabular}{|c|c|c|}
\hline Отряд & Семейство & Вид \\
\hline $\begin{array}{l}\text { I. Petromyzontiformes } \\
\text { Миногообразные }\end{array}$ & $\begin{array}{l}\text { 1. Petromyzontidae - Ми- } \\
\text { ноговые }\end{array}$ & $\begin{array}{l}\text { 1. Lethenteron camtschaticum (Tilesius, 1811) - Тихооке- } \\
\text { анская минога }\end{array}$ \\
\hline \multirow{7}{*}{$\begin{array}{l}\text { II. Cypriniformes } \\
\text { Карпообразные }\end{array}$} & $\begin{array}{l}\text { 2. Balitoridae - Балито- } \\
\text { ровые }\end{array}$ & $\begin{array}{l}\text { 2. Barbatula toni (Dybowski, 1869) - Сибирский усатый } \\
\text { голец }\end{array}$ \\
\hline & \multirow{5}{*}{$\begin{array}{l}\text { 3. Cyprinidae - Карпо- } \\
\text { вые }\end{array}$} & $\begin{array}{l}\text { 3. Carassius carassius jacuticus Kirillov, } 1956 \text { - Якутский } \\
\text { карась }\end{array}$ \\
\hline & & $\begin{array}{l}\text { 4. Leuciscus leuciscus baicalensis (Dybowski, 1874) - Си- } \\
\text { бирский елец }\end{array}$ \\
\hline & & $\begin{array}{l}\text { 5. Phoxinus phoxinus (Linnaeus, 1758) - Обыкновенный } \\
\text { гольян }\end{array}$ \\
\hline & & $\begin{array}{l}\text { 6. Rhynchocypris czekanowskii Dybowski, } 1869 \text { - Гольян } \\
\text { Чекановского }\end{array}$ \\
\hline & & 7. Rhynchocypris percnurus (Pallas 1814) - Озерный гольян \\
\hline & $\begin{array}{l}\text { 4. Catostomidae - Чуку- } \\
\text { чановые }\end{array}$ & $\begin{array}{l}\text { 8. Catostomus catostomus rostratus (Tilesius, 1813) - Си- } \\
\text { бирский чукучан }\end{array}$ \\
\hline $\begin{array}{l}\text { III. Esociformes } \\
\text { Щукообразные }\end{array}$ & 5. Esocidae - Щуковые & 9. Esox lucius Linnaeus, 1758 - Обыкновенная щука \\
\hline \multirow{7}{*}{$\begin{array}{l}\text { IV. Salmoniformes } \\
\text { Лососеобразные }\end{array}$} & \multirow{4}{*}{$\begin{array}{l}\text { 6. Coregonidae - Сиго- } \\
\text { вые }\end{array}$} & $\begin{array}{l}\text { 10. Coregonus lavaretus pidschian (Gmelin, 1789) - Сиг- } \\
\text { пыжьян }\end{array}$ \\
\hline & & 11. Coregonus nasus (Pallas, 1776) - Чир \\
\hline & & $\begin{array}{l}\text { 12. Prosopium cylindraceum (Pennant, 1784) - Обыкно- } \\
\text { венный валек }\end{array}$ \\
\hline & & 13. Stenodus leucichthys nelma (Pallas, 1773) - Нельма \\
\hline & $\begin{array}{l}\text { 7. Thymallidae - Хариу- } \\
\text { совые }\end{array}$ & 14. Thymallus arcticus (Pallas, 1776) - Сибирский хариус \\
\hline & \multirow{2}{*}{$\begin{array}{l}\text { 8. Salmonidae - Лoco- } \\
\text { севые }\end{array}$} & 15. Brachymystax lenok (Pallas, 1773) - Ленок \\
\hline & & $\begin{array}{l}\text { 16. Salvelinus alpinus (Linnaeus, 1758) - Арктический } \\
\text { голец }\end{array}$ \\
\hline $\begin{array}{l}\text { V. Gadiformes } \\
\text { Трескообразные }\end{array}$ & 9. Lotidae - Налимовые & $\begin{array}{l}\text { 17. Lota lota leptura Hubbs et Schultz, } 1941 \text { - Тонкохво- } \\
\text { стый налим }\end{array}$ \\
\hline $\begin{array}{l}\text { VI. Gasterosteiformes } \\
\text { Колюшкообразные }\end{array}$ & $\begin{array}{l}\text { 10. Gasterosteidae - Кo- } \\
\text { Люшковые }\end{array}$ & $\begin{array}{l}\text { 18. Pungitius pungitius (Linnaeus, 1758) - Девятииглая } \\
\text { колюшка }\end{array}$ \\
\hline $\begin{array}{l}\text { VII. Scorpaeniformes } \\
\text { Скорпенообразные }\end{array}$ & $\begin{array}{l}\text { 11. Cottidae - Рогатко- } \\
\text { вые }\end{array}$ & $\begin{array}{l}\text { 19. Cottus kolymensis Sideleva et Goto, } 2012 \text { - Колымский } \\
\text { подкаменщик }\end{array}$ \\
\hline \multirow{2}{*}{$\begin{array}{l}\text { VIII. Perciformes } \\
\text { Окунеобразные }\end{array}$} & \multirow[t]{2}{*}{ 12. Percidae - Окуневые } & $\begin{array}{l}\text { 20. Gymnocephalus cernua (Linnaeus, 1758) - Обыкновен- } \\
\text { ный ерш }\end{array}$ \\
\hline & & 21. Perca fluviatilis Linnaeus, 1758 - Речной окунь \\
\hline
\end{tabular}

Таблица 2. Размерный состав (в \%) обыкновенного гольяна р. Буюнда в 2018 г.

Table 2. Size composition (\%) of the common minnow Phoxinus phoxinus in the Buyunda River in 2018

\begin{tabular}{|l|c|c|c|c|c|c|c|c|c|}
\hline Длина $S L$, мм & $>35$ & $36-40$ & $41-45$ & $46-50$ & $51-55$ & $56-60$ & $61-65$ & $66-70$ & Экз. \\
\hline Самки & - & - & 11.1 & 16.7 & 25.0 & 25.0 & 16.7 & 5.5 & 36 \\
\hline Самцы & - & - & 13.2 & 15.8 & 42.1 & 28.9 & - & - & 38 \\
\hline Оба пола & 5.0 & 3.7 & 10.0 & 15.0 & 31.3 & 25.0 & 7.5 & 2.5 & 80 \\
\hline
\end{tabular}

участков реки и притоков. Может обитать как в чистой, так и в сильно загрязненной взвесями воде.

Основу наших уловов формировали особи в возрасте 7-9+ лет, составляющие 79\% (табл. 3).
Чукучан растет относительно быстро, годовики в начале июля имели длину тела около 95 мм. У зрелых рыб в возрасте 7-9+ лет ежегодные приросты длины тела составили в среднем 35 мм, массы - 144 г. В уловах 2018 г. самый крупный самец имел длину 442 мм и мас- 
Таблица 3. Длина и масса тела разновозрастных особей сибирского чукучана р. Буюнда в уловах 2018 г.

Table 3. Body length and weight of multiple-age Siberian suckers Catostomus catostomus rostratus in the Buyunda River in 2018 cateches

\begin{tabular}{|l|c|c|c|c|c|c|c|}
\hline \multicolumn{1}{|c|}{ Возраст, лет } & $1+$ & $7+$ & $8+$ & $9+$ & $10+$ & $11+$ & $12+$ \\
\hline Длина $F L$, мм & $95 \pm 1.2$ & $358 \pm 3.0$ & $395 \pm 3.7$ & $427 \pm 10.2$ & 419 & 475 & 471 \\
\hline Масса, г & $6.4 \pm 0.4$ & $482 \pm 17$ & $661 \pm 20$ & $770 \pm 54$ & 800 & 1060 & 993 \\
\hline Экз. & 3 & 9 & 11 & 6 & 1 & 1 & 2 \\
\hline
\end{tabular}

Примечание. Здесь и в табл. 4-8 приведены среднее арифметическое показателя и его ошибка.

су 952 г (возраст 9+), самка - 475 мм и 1060 г $(12+)$.

Размножение происходит в конце мая - июне во время весеннего половодья в притоках реки с галечно-песчаным грунтом. Созревает на 5-8-м году жизни, нерест единовременный.

Численность в типичных местообитаниях р. Буюнда, не затронутых разработками золота открытым способом, повсеместно высокая. Перспективен для местного рыболовного промысла.

Обыкновенная щука. Пресноводный, озерноречной вид. Щука широко распространена в бассейне Колымы, особенно она многочисленна в нижнем течении реки. В р. Буюнда встречается на участках с замедленным течением, в крупных притоках и связанных с ними озерах. В речных водотоках щука предпочитает держаться прибрежных биотопов, районов впадения небольших проток в основное русло. В озерах она обычна в зарослях высшей водной растительности. Весной половозрелые особи образуют нерестовые скопления, но значительных миграций не совершают. Летом она держится разрозненно, перемещаясь вслед за своей добычей.

В сетных уловах щука была представлена особями длиной $S L$ 161-695 мм и массой 39-3150 г (табл. 4).
В исследуемой выборке доля щук с пустым желудком составила 62.2\%. Остальные особи питались преимущественно рыбой (ее встречаемость составила 46.5\%), беспозвоночными (14.3\%), мышевидными грызунами (10.7\%), миногами (3.6\%). Среди рыб в питании щуки наиболее часто встречался речной гольян (17.9\%), количество которого в желудке хищника варьировало от 1 до 19 (в среднем 7.2) экз. Также единично попадался тонкохвостый налим и особи собственного вида.

Численность щуки в р. Буюнда не высокая. Перспективна как объект спортивно-любительского лова.

Обыкновенный валек. Обычный, типично пресноводный вид североамериканского происхождения. В р. Буюнда населяет участки основного русла и притоки с быстрым течением, чистой и холодной водой. Также может встречаться в связанных с рекой пойменных и террасных озерах ледникового или тектонического происхождения. Сезонные нагульные миграции небольшие, направленные в основном в верховья реки и притоки.

В наших уловах встречались рыбы длиной $F L$ 76-335 мм и с массой тела -6.5-320 г (табл. 5).

Таблица 4. Длина и масса тела разновозрастных особей обыкновенной щуки р. Буюнда в уловах 2018 г.

Table 4. Body length and weight of multiple-age Northern pikes Esox lucius in the Buyunda River in 2018 cateches

\begin{tabular}{|l|c|c|c|c|c|c|c|}
\hline \multicolumn{1}{|c|}{ Возраст, лет } & $1+$ & $2+$ & $3+$ & $4+$ & $5+$ & $6+$ & $10+$ \\
\hline Длина $S L, \mathrm{MM}$ & 161 & $273 \pm 15$ & $346 \pm 3.5$ & $387 \pm 4.7$ & 464 & 558 & 685 \\
\hline Масса, г & 39 & $194 \pm 36$ & $418 \pm 14$ & $557 \pm 25$ & 849 & 1950 & 3150 \\
\hline Экз. & 1 & 4 & 51 & 14 & 1 & 1 & 2 \\
\hline
\end{tabular}

Таблица 5. Длина и масса тела разновозрастных особей обыкновенного валька р. Буюнда в уловах 2018 г.

Table 5. Body length and weight of multiple-age round whitefishes Prosopium cylindraceum in the Buyunda River in 2018 cateches

\begin{tabular}{|l|c|c|c|c|c|c|}
\hline \multicolumn{1}{|c|}{ Возраст, лет } & 1 & 2 & 3 & 5 & 6 & 7 \\
\hline Длина $F L$, мм & 80,5 & 127 & 180 & $288 \pm 5.5$ & $306 \pm 3.9$ & 325 \\
\hline Масса, г & - & 7.3 & 41.8 & $203 \pm 15.2$ & $242 \pm 9.4$ & 290 \\
\hline Экз. & 2 & 1 & 2 & 5 & 9 & 2 \\
\hline
\end{tabular}


Годовики валька в начале июля имели длину тела около 80 мм. До начала созревания (5+ лет) у рыб наблюдались наибольшие годовые линейные приросты (в среднем 52 мм в год), после чего они резко снижались до 19 мм в год. По характеру питания валек - типичный бентофаг. Размножение происходит осенью - в конце сентября при температуре воды $+2 \ldots+4^{\circ} \mathrm{C}$. Нерестилища располагаются в русловой части рек на галечнопесчаном грунте со скоростями течения не ниже $0.3-0.5 \mathrm{~m} / \mathrm{c}$.

Ресурсы валька в р. Буюнда небольшие и промыслом не используются.

Сибирский хариус. Пресноводный, преимущественно речной вид. В Колымском бассейне встречается во всех реках и многих озерах. В p. Буюнда отмечен повсеместно, многочислен в притоках. Предпочитает участки водоема с небольшой скоростью течения и высокой прозрачностью воды. Избегает сильно заиленных, мутных водотоков с большим количеством взвесей и низким содержанием кислорода. Протяженных сезонных миграций не совершает, и его перемещения в районы нереста или откорма не превышают, как правило, нескольких десятков километров. Весной с началом половодья начинается подъем хариуса в притоки горного характера для размножения. Зимует на глубоких ямах основного русла с хорошей проточностью.

Основу уловов 2018 г. формировали особи в возрасте 3-6+ лет, составляющие 91\% (табл. 6).

Созревание рыб происходит в 4-6 полных лет при длине 240-280 мм. По характеру питания хариус - типичный полизоофаг, потребляющий любой доступный в данный сезон корм животного происхождения.

Запасы хариуса в р. Буюнда не велики и рассредоточены по притокам и поэтому используются только любительским промыслом.
Ленок. Восточносибирский пресноводный вид. В бассейне р. Буюнда предпочитает горные и предгорные участки реки и ее крупных притоков. Весной после ледохода зрелые особи поднимаются в горные притоки для размножения, а осенью мигрируют обратно в глубокие ямы основного русла для зимовки. Неполовозрелые ленки и одиночные пропускающие нерест взрослые рыбы летом держатся преимущественно в среднем и нижнем течении реки, в основном в приустьевых пространствах притоков.

В наших уловах встречались рыбы возраста 2-7+ лет (табл. 7).

Рост ленков в реке относительно быстрый и к 8 годам они достигают длины 473 мм и массы 1187 г.

Численность ленка в р. Буюнда невелика. Является ценной промысловой рыбой, особенно как объект спортивно-любительского лова.

Обыкновенный ерш. Пресноводный, преимущественно речной вид. Предпочитает чистые участки реки с замедленным течением, старицы, протоки и пойменные озера. Очень чувствителен к естественному и антропогенному загрязнению воды. Значительных миграций не совершает, ограничиваясь небольшими сезонными и суточными перемещениями вдоль русла водоемов в поисках пищи.

В наших уловах длина рыб (5 экз.) варьировала от 98.2 до 111.6 (в среднем 106.3) мм, масса $-14.2-23.2(17.4)$ г. Все особи были в возрасте 6-7+ лет. Половое созревание наступает на втором году жизни (Кириллов Ф., 1972). Ерш - типичный бентофаг, предпочитающий личинок хирономид и гаммарид. Также потребляет зоопланктон, икру и молодь рыб.

Численность ерша в реке невысокая и промыслом не используется.

Таблицุа 6. Длина и масса тела разновозрастных особей сибирского хариуса р. Буюнда в уловах 2018 г.

Table 6. Body length and weight of multiple-age Siberian graylings Thymallus arcticus in the Buyunda River in 2018 cateches

\begin{tabular}{|l|c|c|c|c|c|c|c|}
\hline \multicolumn{1}{|c|}{ Возраст, лет } & $2+$ & $3+$ & $4+$ & $5+$ & $6+$ & $8+$ & $10+$ \\
\hline Длина $F L$, мм & $164 \pm 4.3$ & $209 \pm 2.1$ & $243 \pm 3.3$ & $264 \pm 7.5$ & $282 \pm 5.1$ & 357 & 375 \\
\hline Масса, г & $40 \pm 3.5$ & $90 \pm 2.6$ & $150 \pm 7.4$ & $198 \pm 19$ & $253 \pm 18$ & 442 & 630 \\
\hline Экз. & 4 & 28 & 26 & 9 & 8 & 2 & 1 \\
\hline
\end{tabular}

Таблица 7. Длина и масса тела разновозрастных особей ленка р. Буюнда в уловах 2018 г.

Table 7. Body length and weight of multiple-age lenoks Brachymystax lenok in the Buyunda River in 2018 cateches

\begin{tabular}{|l|c|c|c|c|c|c|}
\hline \multicolumn{1}{|c|}{ Возраст, лет } & $2+$ & $3+$ & $4+$ & $5+$ & $6+$ & $7+$ \\
\hline Длина $F L$, мм & 248 & 312 & 365 & 388 & 457 & 473 \\
\hline Масса, г & 154 & 317 & 540 & 626 & 1096 & 1187 \\
\hline Экз. & 2 & 3 & 2 & 1 & 1 & 3 \\
\hline
\end{tabular}


Таблица 8. Длина и масса тела разновозрастных особей речного окуня р. Буюнда в уловах 2018 г. Table 8. Body length and weight of multiple-age perches Perca fluviatilis in the Buyunda River in 2018 catches

\begin{tabular}{|l|c|c|c|c|c|c|c|c|c|}
\hline \multicolumn{1}{|c|}{ Возраст, лет } & $1+$ & $2+$ & $5+$ & $6+$ & $7+$ & $8+$ & $9+$ & $10+$ & $11+$ \\
\hline Длина $S L$, мм & $100 \pm 1.8$ & $120 \pm 1.8$ & 214 & 225 & $236 \pm 0.4$ & $257 \pm 2.6$ & $279 \pm 1.8$ & 297 & 322 \\
\hline Масса, г & $18 \pm 1.0$ & $31 \pm 2.2$ & 226 & 273 & $312 \pm 4.5$ & $393 \pm 11$ & $508 \pm 16$ & 610 & 737 \\
\hline Экз. & 21 & 4 & 3 & 1 & 4 & 11 & 4 & 3 & 1 \\
\hline
\end{tabular}

Речной окунь. Пресноводный, озерно-речной вид, широко распространенный в бассейне р. Колыма. В Буюнде взрослые окуни предпочитают глубоководные слабо текучие участки основного русла и крупных притоков, также встречаются в некоторых крупных озерах. Неполовозрелые особи в основном держатся на прибрежных участках проток и стариц, поросших водной растительностью. Незначительные миграции вида обычно сводятся к перемещениям к местам нагула, нереста и зимовки.

Наши сборы на прибрежных, мелководных участках реки показали наличие неполовозрелых окуней возраста 1-2+ лет. Сетные уловы по руслу реки, а также крупным притокам включали особей 5-11+ лет, которые были все половозрелыми (табл. 8).

По характеру питания окунь является полифагом, хотя существуют возрастные изменения спектра питания. Так, мальки питаются преимущественно зоопланктоном. Подрастающая молодь переходит на питание бентосными организмами. Взрослые окуни, кроме бентоса, потребляют рыбу, которая составляет основу рациона.

Является ценной промысловой рыбой, особенно как объект спортивно-любительского лова.

\section{ЗАКЛЮЧЕНИЕ}

В бассейне р. Буюнда обитает 21 вид пресноводных рыбообразных и рыб, относящихся к 19 родам, 12 семействам, 8 отрядам и 2 классам. Преобладают представители отрядов карпообразных и лососеобразных (в каждом 3 семейства, 6 родов и 7 видов), которые определяют облик всей ихтиофауны реки, составляя в ней $50 \%$ по числу семейств, $63 \%$ - родов и $67 \%$ - видов. В составе ихтиофауны присутствуют два региональных эндемика Северо-Востока Азии - сибирский чукучан и колымский подкаменщик. Типично пресноводные рыбы представлены 13 видами: сибирским усатым гольцом, якутским карасем, сибирским ельцом, речным гольяном, гольяном Чекановского, озерным гольяном, сибирским чукучаном, обыкновенной щукой, обыкновенным вальком, сибирским хариусом, ленком, обыкновенным ершом и речным окунем. Остальные 8 видов - эвригалинные, способные обитать в воде с различной соленостью. Рыбы р. Буюнда по степени экологической специализации также разнообразны и могут быть условно отнесены к следующим группам (Кириллов и др., 2016): полупроходнылм - нельма; речнылм - жилая форма тихоокеанской миноги, сибирский усатый голец, сибирский елец, речной гольян, сибирский чукучан, обыкновенный валек, сибирский хариус, ленок, тонкохвостый налим, колымский подкаменщик, обыкновенный ерш; озерно-речным - обыкновенная щука, сиг-пыжьян, чир, девятииглая колюшка, речной окунь; озернылм - якутский карась, гольян Чекановского, озерный гольян, арктический голец.

Работа выполнена при финансовой поддержке гранта ДВО РАН «Дальний Восток» (№ 18-4-002).

\section{ЛИТЕРАТУРА}

Дрягин П. А. Рыбные ресурсы Якутии // Тр. Совета по изучению производительных сил. Ленинград : АН СССР, 1933. Вып. 5. С. 1-93.

Иогансон В. Е., Кузнеиов А. С., Деев Г. И. Реки // Север Дальнего Востока. Москва : Наука, 1970. C. 186-202.

Кириллов А. Ф., Апсолихова О. Д., Жирков Ф. Н., Карпова Л. Н., Свешников Ю. А., Бурмистров Е. В. Аннотированный список рыбообразных и рыб бассейна Восточно-Сибирского моря // Исследования водных биологических ресурсов Камчатки и северозападной части Тихого океана. 2016. Вып. 42. С. 78 87. DOI: $10.15853 / 2072-8212.2016 .42 .78-87$

Кириллов Ф. Н. Рыбы Якутии. Москва : Наука, 1972. $360 \mathrm{c}$.

Лакин Г. Ф. Биометрия. Москва : Высш. шк., 1990. $352 \mathrm{c}$.

Никишин В. П., Леонов С. А. Гельминты промысловых рыб бассейна Буюнды : препринт. Магадан : СВНЦ ДВО РАН, 2000. 78 c.

Новиков А. С. Рыбы реки Колымы. Москва : Наука, 1966. $136 \mathrm{c}$.

Парин Н. В., Евсеенко С. А., Васильева Е. Д. Рыбы морей России: аннотированный каталог. Москва : Тов-во науч. изданий КМК, 2014. 733 с.

Правдин И. $Ф$. Руководство по изучению рыб. Москва : Пищ. пром-сть, 1966. 375 с.

Скопеи М. Б. Рыбы верховьев Колымы и перспективы формирования ихтиофауны колымских водохранилищ // Биологические проблемы Севера : тез. докл. Х Всесоюз. симп. Магадан, 1983. Ч. 2. С. 282-283.

Скопеи М. Б. О биологии рыб бассейна Верхней Колымы // Пояс редколесий верховий Колымы (район строительства Колымской ГЭС). Владивосток : ДВНЦ AH CCCP, 1985. C. 129-138.

Черешнев И. А., Кириллов А. Ф. Рыбообразные и рыбы морских и пресных вод бассейнов морей Лаптевых и Восточно-Сибирского // Вестник Северо-Восточного научного центра ДВО РАН. 2007. № 2. С. 95-106. 
Штундюк Ю. В., Скопеи М. Б. Краткая характеристика рыб реки Колымы в связи со строительством Усть-Среднеканской ГЭС // Краевед. записки. Магадан : Кн. изд-во, 1988. Вып. 15. С. 178-188.
Eschmeyer's catalog of fishes: genera, species, references / eds. R. Fricke, W. N. Eschmeyer, R. Van der Laan. 2020. URL: http://researcharchive.calacademy.org/research/ichthyology/catalog/fishcatmain.asp

Поступила в редакиию 24.07.2020 г.

Поступила после доработки 22.09.2020 2.

\title{
REVIEW OF THE BUYUNDA RIVER PISCIFAUNA (Kolyma River Basin)
}

\author{
A. V. Shestakov, S. I. Grunin \\ Institute of Biological Problems of the North, FEB RAS, Magadan
}

\begin{abstract}
The modern taxonomic composition and biologic features of pisciforms and fishes of the Buyunda River (basin of the Kolyma River) are considered. The ichthyofauna includes 21 taxa of species and subspecies ranks belonging to 19 genera, 12 families, 8 orders, and 2 classes. Representatives of the of Cypriniformes and Salmoniformes orders prevail, shaping the entire ichthyofauna of the river. Two regional endemic species of Northeast Asia the Siberian sucker Catostomus catostomus rostratus and the Kolyma bullhead Cottus kolymensis, were recorded.
\end{abstract}

Keywords: freshwater fishes, Buyunda River, Kolyma River basin, fish fauna, ecotypes.

\section{REFERENCES}

Chereshnev, I. A., Kirillov, A. F., 2007. Pisciforms and Fishes from the Laptev and the East-Siberian Seas and Their Related Freshwater Areas, Vestnik NESC FEB RAS. 2, 95-106 [In Russian].

Dryagin, P. A., 1933. Fish Resources of Yakutia, Trudy Soveta po Izucheniyu Proizvoditel'nykh Sil. Leningrad. 5, 1-93 [In Russian].

Eschmeyer's Catalog of Fishes: Genera, Species, References, Eds. R. Fricke, W. N. Eschmeyer, R. Van der Laan, 2020. URL: http://researcharchive.calacademy.org/ research/ichthyology/catalog/fishcatmain.asp

Ioganson, V. E., Kuznetsov, A. S., Deev, G. I., 1970. Rivers, North of the Far East. Moscow, Nauka, 186-202 [In Russian].

Kirillov, A. F., Apsolikhova, O. D., Zhirkov, F. N., Karpova, L. N., Sveshnikov, Yu. A., Burmistrov, E. V., 2016. Annotated List of Pisciforms and Fishes of the East-Siberian Sea Basin, Research of Aquatic Biological Resources of Kamchatka and the North-West Pacific. 42, 78-87. DOI: 10.15853/2072-8212.2016.42.78-87

Kirillov, F. N., 1972. Fishes of Yakutia. Moscow, Nauka [In Russian].

Lakin, G. F., 1990. Biometrics. Moscow, Vyssh. Shkola [In Russian].
Nikishin, V. P., Leonov, S. A., 2000. Helminths of Commercial Fish in the Buyunda Basin. Magadan, NESC FEB RAS [In Russian].

Novikov, A. S., 1966. Fishes of the Kolyma River. Moscow, Nauka [In Russian].

Parin, N., V., Evseenko, S. A., Vasilyeva, E. D., 2014. Fishes of Russia's Seas : Annotated Catalog. Moscow, KMK Scientific Press [In Russian].

Pravdin, I. F., 1966. Guide to Studying Fishes. Moscow, Pishchevaya Promyshlennost' [In Russian].

Shtundyuk, Yu. V., Skopets, M. B., 1988. Brief Characteristics of the Fish of the Kolyma River in Connection with the Construction of the Ust-Srednekan Hydroelectric Power Plant, Krayevedcheakiye Zapiski. 15, 178-188 [In Russian].

Skopets, M. B., 1983. Fishes of the Upper Reaches of the Kolyma and Prospects for the Formation of the Ichthyofauna of the Kolyma Reservoirs, Biological Problems of the North. 2, 282-283 [In Russian].

Skopets, M. B., 1985. On the Biology of Fish in the Upper Kolyma Basin, Light Forest Belt of the Upper Kolyma River (Construction Area of the Kolyma Hydroelectric Power Plant). Vladivostok, FESC AS USSR. 129-138 [In Russian]. 